\title{
Altering retrieval demands reverses the picture superiority effect
}

\author{
MARY SUSAN WELDON and HENRY L. ROEDIGER, III \\ Purdue University, West Lafayette, Indiana
}

\begin{abstract}
In Experiment 1 subjects studied a mixed list of pictures and words and then received either a free recall test or a word fragment completion test (e.g., $\mathbf{y r} \_\mathrm{mi}$ for pyramid) on which some fragments corresponded to previously studied items. Free recall of pictures was better than that of words. However, words produced greater priming than did pictures on the fragment completion test, although a small amount of picture priming did occur. Experiments 2 and 3 showed that the picture priming was not due to implicit naming of the pictures during study. In Experiment 4 subjects studied words and pictures and received either the word fragment completion test or a picture fragment identification test in which they had to name degraded pictures. Greater priming was obtained with words in word fragment completion, but greater priming was obtained with pictures on the picture identification test. We conclude that (1) the type of retrieval query determines whether pictures or words will exhibit superior retention, and (2) our results conform to the principle of transfer appropriate processing by which performance on transfer or retention tests benefits to the extent that the tests recapitulate operations used during learning.
\end{abstract}

The picture superiority effect refers to the finding that pictures are typically remembered better than are words (e.g., Paivio, 1971; Paivio \& Csapo, 1973; Paivio, Rogers, \& Smythe, 1968). In the typical experiment demonstrating the effect, subjects study either easily named pictures or their labels, and later they are asked to recall the words and names of the pictures. If the finding were not so commonplace, it might seem counterintuitive, because verbal retrieval tests would actually seem to favor word over picture memory. That is, words can be recalled in the same format in which they were studied, but pictures must be recoded in order to be recalled. Despite this fact, recall in many tasks is better following the study of pictures than of words.

An even more surprising example of this seeming anomaly is that the picture superiority effect is obtained in recognition memory when the test consists entirely of words (Borges, Stepnowsky, \& Holt, 1977; Madigan, 1983; Paivio, 1973; Snodgrass \& McClure, 1975). For example, Madigan's (1983) subjects studied pictures and words, and then received a recognition test in which all items were presented as words. Items that had been studied as pictures or drawings were recognized more accurately than those studied as words, despite the fact that the physi-

\footnotetext{
This research was supported by NIH Grant R01 HD15054 awarded by the National Institute for Child Health and Human Development, and was presented at the Midwestern Psychological Association meeting in Chicago in May 1986. The first two experiments constituted a master's thesis submitted to Purdue University by the first author. We thank committee members Gordon D. Logan and Howard B. Ranken for their input, and Alice Healy, James $\mathbf{H}$. Neely, Douglas Nelson, Allan Paivio, and Norman J. Slamecka for their helpful comments on an earlier version of the manuscript. Requests for reprints may be sent to Mary Susan Weldon at the Department of Psychological Sciences, Purdue University, West Lafayette, IN 47907.
}

cal features of the study and test stimuli matched better when words had been studied.

These outcomes seem inconsistent with the generally accepted idea that remembering is better when test conditions match study conditions than when they mismatch (e.g., McGeoch, 1942; Tulving \& Thomson, 1973). How can this apparent anomaly be explained? Theoretical accounts have suggested that picture superiority can be attributed to richer stimulus encoding for pictures than for words. For example, in his dual coding hypothesis, Paivio $(1969,1983,1986)$ suggested that verbal and imaginal information are stored in functionally independent, but partly interconnected, symbolic systems in long-term memory; pictures are more likely to arouse both the verbal and imaginal codes of the referent than are words, and such encoding redundancy improves the memorability of the pictures. In his sensory-semantic model, Nelson (1979) suggested that although pictures and words share identical semantic (meaning) codes, pictures are more memorable because they have more distinctive sensory codes than do words. In general, most accounts of picture superiority assume that the effect is localized in encoding processes, and any possible role of retrieval processes has been largely ignored.

The assumption that picture superiority results from richer coding finds support in the fact that the effect seems relatively insensitive to changes in retrieval tasks, but can be eliminated or even reversed by various encoding manipulations. For example, Durso and Johnson (1980) established an incidental learning situation in which different groups of subjects saw either pictures or words and answered different questions about each item's name (e.g., "What is the name of the item?"), or image (e.g., "How long would it take to draw the object?"), or referent (e.g., questions about the object's function). Subjects were then 
given a surprise auditory recognition test. Pictures were recognized better than words following the labeling tasks, the two types of items were recognized equally well in the referential tasks, and words were actually recognized better than pictures in the imagery tasks, reversing the typical picture superiority effect. The authors explained this reversal within the framework of the sensory-semantic model, suggesting that an imagery instruction causes elaboration of the engram for words more than for pictures, hence increasing word memorability. In general, elaborative encoding tasks, such as imaging (Paivio \& Csapo, 1973) or categorizing the item into superordinate categories (Smith \& Magee, 1980), eliminate or reverse superior memory for pictures. Other encoding manipulations that have eliminated or reversed the effect include paired-associate learning with schematically similar pictures (Nelson, Reed, \& Walling, 1976) and serial learning at very rapid presentation rates (Nelson, Reed, \& McEvoy, 1977; Paivio \& Csapo, 1971).

Although the picture superiority effect can be eliminated or reversed by manipulating encoding demands, it has proven relatively insensitive to changes in retrieval demands. Its persistence across free recall, serial recall, and visual and auditory recognition tests would seem to argue that the form of test has little influence. However, we demonstrate through our experiments that a relatively new class of tasks can reverse the picture superiority effect, thus showing that retrieval demands do play a role.

A recent distinction between implicit and explicit retrieval tests (e.g., Graf \& Schacter, 1985) may be useful in revealing that retrieval demands play a role in the picture superiority effect. Explicit memory tests are those that require conscious recollection of studied material, such as free recall, recognition, and paired-associate learning. In contrast, implicit retention tasks do not require conscious recollection, but reveal retention indirectly when performance on some task is facilitated by previous exposure to the material. Typical examples of implicit tests are perceptual identification (Jacoby \& Dallas, 1981), identification of perceptually degraded word fragments (Warrington \& Weiskrantz, 1970), word stem completion (e.g., cheek for che__; Graf \& Mandler, 1984), word fragment completion (e.g., h_ck $r_{-}$for checkers; Tulving, Schacter, \& Stark, 1982), and lexical decision (e.g., Scarborough, Cortese, \& Scarborough, 1977).

This distinction is significant because a variety of dissociations have been obtained between implicit and explicit tasks. For example, amnesics show marked deficits relative to controls on recall and recognition, whereas they exhibit equal levels of priming on implicit tasks such as identification of degraded word fragments (Warrington $\&$ Weiskrantz, 1970) and word stem completion (Graf, Squire, \& Mandler, 1984).

Implicit memory tests also reveal quite different properties of normal memory from those inferred from explicit tests. For example, implicit tests appear to be much more sensitive to the processing of stimulus surface features than are explicit tests, whereas explicit tests show large effects of conceptual processing of stimuli (e.g., the use of contextual and semantic information). For example, Jacoby (1983) found that when subjects generated a target word from a context word (e.g., read "cold-___," generate "hot"), they later recognized the targets significantly more accurately than when they simply read the target without context (e.g., read " $x x x$-hot") during the study phase. However, the opposite pattern of results was obtained on priming in perceptual identification: significant increases in accurate word identifications were obtained for targets that had been read, but not for those that had been generated. In a similar vein, Roediger and Blaxton (in press) found that visual presentations produced significantly more repetition priming than did auditory presentations on a word fragment completion task (e.g., h_ck $r_{-}$for checkers). Under comparable conditions, no modality effect occurred in free recall (Blaxton, 1985).

It is especially interesting to note that implicit memory tests appear to be most sensitive to manipulations of perceptual attributes of stimuli, such as the attenuation or elimination of cross-modality priming in perceptual identification (Jacoby \& Dallas, 1981), word stem completion (Graf, Shimamura, \& Squire, 1985), word fragment completion (Roediger \& Blaxton, in press), and lexical decision (Kirsner, Milech, \& Standen, 1983). On the other hand, explicit tests such as free recall and recognition tend to be much less sensitive to perceptual manipulations (e.g., little effect of modality in long-term free recall), but very sensitive to the conceptual properties of the encoding tasks (e.g., levels of processing; Craik \& Tulving, 1975). One way of explaining these dissociations is by distinguishing between tasks that are relatively more data-driven and those that are relatively more conceptually driven (Jacoby, 1983). Briefly, data-driven tasks tap memory for aspects of perceptual processing, or the processing of surface features, whereas conceptually driven tasks are affected by elaborative encoding manipulations (see Roediger \& Blaxton, 1987).

From these considerations, we hypothesized that the picture superiority effect might be reversed on an implicit, verbal, data-driven task. For example, if subjects study pictures and words and then perform the word fragment completion task, words should produce more priming than do pictures because there is greater overlap between the physical features of the study word and test fragment than between the picture and test fragment. Other evidence suggests that the picture superiority effect may be reversible by using a data-driven implicit memory test; pictures have been shown to produce less priming than do words as measured by word-naming latency (Durso \& Johnson, 1979), lexical decision latency (Scarborough, Gerard, \& Cortese, 1979), perceptual identification accuracy for words (Kirsner, Milech, \& Stumpfel, 1986), and perceptual identification thresholds for words (Winnick \& Daniel, 1970). Although these researchers did not draw 
implications from their experiments regarding the role of retrieval processes in the picture superiority effect, their findings point to the plausibility of our hypothesis.

In the experiments reported here, we employed the word fragment completion task to test our hypothesis that the picture superiority effect would reverse on an implicit data-driven memory test. Tulving et al. (1982) observed a dissociation between this task and recognition memory: recognition memory significantly decayed over 1 week, whereas priming on the word fragment completion task did not. Furthermore, the probability of completing a fragment was independent of whether it had been identified as old or new on the recognition test. Roediger and Blaxton (1987) reviewed a variety of studies in which changes in language, modality, and typeface between the study stimuli and test fragments significantly attenuated or eliminated repetition priming on the fragment completion test, but produced very different patterns of results on conceptually driven explicit tests such as free recall and recognition. Thus, the word fragment completion test is appropriate for examining the effects of implicit data-driven retrieval demands on picture memory.

\section{EXPERIMENT 1}

Experiment 1 was designed to determine whether the picture superiority effect could be reversed by varying only the type of retrieval task. Subjects saw mixed lists of drawings and words, and then received free recall and word fragment completion tests. If the fragment completion test taps memory primarily for the processing of surface features, picture superiority should be reversed because the match between the study and test stimuli is greater for the words than for the drawings. However, the usual picture superiority effect should be observed in free recall.

\section{Method}

Subjects. Ninety male and female undergraduate students at Purdue University participated for credit in introductory psychology. All subjects were native English speakers and had normal or corrected-to-normal vision.

Design. The experiment comprised a $3 \times 2$ mixed design for the word fragment completion test and a $2 \times 2$ mixed design for the free recall test. All subjects received both the free recall and word fragment completion tests. For word fragment completion, study format (picture, word, nonstudied) was the within-subjects factor and test order (word fragment completion first vs. free recall first) was the between-subjects factor. For free recall, of course, the nonstudied condition was not included as a level of the format factor. Fortyfive subjects were randomly assigned to each test order condition.

Materials. Thirty-three common concrete items were selected from Snodgrass and Vanderwart's (1980) picture norms. Two slides were obtained for each item, one displaying a simple black-on-white line drawing, and the other the label (name) typed in uppercase letters.

Each item had a word fragment frame with a unique solution. Word fragments were normed so that for subjects given $20 \mathrm{sec}$ to complete each nonstudied fragment, the average completion rate for the set was $30 \%$, with individual items ranging from $20 \%$ to
$50 \%$. According to Snodgrass and Vanderwart (1980), the selected drawings were labeled correctly by $83 \%-100 \%$ of subjects, with an average of $95 \%$.

Items were divided into three sets of 11 , equated for fragment completion rate and label agreement. The three item sets were rotated through the three format conditions so that each served as a picture, word, or nonstudied item an equal number of times, thus creating three lists. In each list, pictures and words were randomly assigned to positions 11 through 32 . An additional 20 buffer items (10 words, 10 pictures) were selected from the Snodgrass and Vanderwart (1980) set, and were similar to the test items in terms of labeling and word fragment completion rates. Five of each were randomly assigned to the first and last 10 list positions and remained in the same positions for all lists. Total list length was thus $\mathbf{4 2}$ items, consisting of 20 buffer and 22 target items. Each list was studied by 15 subjects in each test order condition.

For the word fragment completion test, fragments for all 33 items were randomly ordered (items from all three sets were mixed together) and were typed in an uppercase font matching that on the slides, with 11 fragments placed on each of three pages. The pages were collated in all six possible orders, and each page order was distributed to subjects before any page order was repeated. For the free recall test, subjects were given a blank sheet of paper.

Procedure. Subjects were tested in groups of 4-15. They were seated in a darkened room, 5-15 ft from the screen. Subjects were told that they would see a series of slides and that they should pay close attention to each item, but they were not told that they would receive a memory test. Slides were presented by a Kodak carousel projector at the rate of $4.25 \mathrm{sec}$ per item, with an interstimulus interval of $0.75 \mathrm{sec}$.

Subjects received both tests, with test order counterbalanced across subjects and lists. For the free recall test, subjects were instructed to write down as many words and picture labels as they could remember; every minute during the 5-min free recall period, they were told to draw a line beneath the last item written. For the fragment completion test, subjects were not informed that some of the test fragments were studied items; instead, they were told that they were helping prepare research materials for another project. They were shown a sample fragment and were read instructions about how to perform the task. They were told that they would have $20 \mathrm{sec}$ to complete each item. They were also instructed to use a blank sheet of paper to cover upcoming items and neither to look ahead nor to return to any items they had been unable to complete initially. After the first test was completed, subjects placed their answer sheets face down under their desks and received instructions for the second test.

\section{Results and Discussion}

Table 1 presents the mean proportion of total items recalled or completed as a function of format and test order. Priming scores (studied - nonstudied items) for the completion test are also included. In all four experiments reported here, (1) results are reported at the $p<.01$ level of significance unless otherwise indicated, and (2) when $t$ tests were performed, one-tailed tests were used to test specific directional predictions (e.g., priming was compared to baseline), and two-tailed tests were used otherwise.

Free recall. Free recall data were analyzed in a $2 \times 2$ mixed-factors ANOVA, with format (pictures vs. words) the within-subjects factor and test order the betweensubjects factor. The effect of study format was significant $[F(1,88)=28.31, M S e=0.02]$. As predicted, pic- 
Table 1

Mean Free Recall and Word Fragment Completion Proportions in Experiment 1

\begin{tabular}{lccc}
\hline & \multicolumn{3}{c}{ Study Format } \\
\cline { 2 - 4 } Test Type and Order & Picture & Word & Nonstudied \\
\hline Free Recall & & & \\
$\quad$ Fragment completion first & .43 & .30 & \\
$\quad$ Free free recall first & .35 & .28 & \\
$\quad$ Word Fragment Completion & & & \\
$\quad$ Raw scores & & & \\
$\quad$ Fragment completion first & .45 & .64 & .38 \\
$\quad$ Free recall first & .44 & .56 & .29 \\
$\quad \begin{array}{l}\text { Priming (studied - nonstudied) } \\
\quad \text { Fragment completion first }\end{array}$ & .07 & .26 & \\
$\quad$ Free recall first & .15 & .27 & \\
\hline
\end{tabular}

tures (mean $=0.39$ ) were recalled significantly better than were words (mean $=0.29$ ), replicating the usual picture superiority effect.

The effect of test order was significant $[F(1,88)=3.94$, $M S e=0.03, p<.05]$. More items were recalled when the free recall test was preceded by the word fragment completion test (mean $=0.37$ ) than when the free recall test was first (mean $=0.32$ ). However, this order effect is difficult to interpret because test order is a betweengroup factor, and the fragment completion baselines discussed below suggest that group differences were present. The interaction between test order and item format was not statistically significant $[F(1,88)=2.56, p=.11]$; more pictures than words were recalled in both test orders.

Word fragment completion. The fragment completion data in Table 1 reveal slight differences between the groups' baseline levels of performance (nonstudied rates), although this difference was not reliable $[t(88)=1.47$, $p>.10$, two-tailed]. Nevertheless, the ANOVA was performed on the priming scores, which were computed by subtracting each subject's nonstudied from studied completion rates. Priming scores subtract out initial individual differences and thus are more accurate indices of changes in performance due to study conditions.

Priming scores were analyzed in a $2 \times 2$ mixed-factors ANOVA, with format (pictures, words) the within-subjects factor and test order the between-subjects factor. The main effect of format was significant $[F(1,88)=48.59, M S \mathrm{e}=$ 0.02 ]. As predicted, the picture superiority effect was reversed; priming was higher for words (mean $=0.26$ ) than for pictures (mean $=0.11$ ). This confirms our hypothesis that the picture superiority effect can be reversed by changing only the retrieval task. This finding suggests that the standard mnemonic benefit of pictures over words involves not only encoding factors but retrieval processes as well. Furthermore, this finding can be explained by the notion that the implicit fragment completion test is a data-driven task that taps memory for the processing of stimulus surface features. Retrieval of words is superior on this task because the word fragments recapitulate perceptual processes that are more similar to those that were engaged in word than in picture percep- tion. The significance of the dissociation between the word fragment completion and free recall tests will be discussed further in the General Discussion.

Neither the effect of test order $[F(1,88)=1.92, M S e=$ $0.06, p=.17]$ nor the interaction of study format and test order $[F(1,88)=2.73, M S \mathrm{e}=0.02, p=.10]$ were significant, although the latter was borderline.

The best estimate of picture priming is from the data in which the word fragment completion test was given first, because performance was uncontaminated by exposure to the verbal form of the stimulus during the free recall test. A $t$ test performed on picture priming obtained when the word fragment completion test was given first revealed that the $7 \%$ priming was significantly greater than zero $[t(44)=2.21, p<.05$, one-tailed $]$. This picture priming was unexpected because if word fragment completion is completely data-driven, the lack of overlap between surface features of the studied pictures and test fragments should have eliminated priming. This effect was examined further in Experiment 2.

\section{EXPERIMENT 2}

Experiment 2 was designed to replicate and explore the source of picture priming obtained in Experiment 1. If word fragment completion is strictly data-driven, that is, if it taps retention only for processing of surface features, then pictures should not have primed word fragments because there is no overlap between their physical features. However, in Experiment 1, pictures did prime word fragments, suggesting either that the word fragment completion task has a conceptual component or that subjects were covertly labeling pictures, which may have facilitated fragment completion by activating graphemic codes indirectly.

In Experiment 2, different groups of subjects were given different study instructions that were designed to vary covert labeling of the study stimuli. In the pictures/ study-details condition, which was designed to reduce covert labeling of pictures, subjects were told they would later perform a picture discrimination task, so they should study pictorial details carefully. Although this technique does not guarantee suppression of covert labeling, it is similar to a technique successfully used by Babbitt (1982) to suppress labeling, and it should at least reduce labeling as compared with the other study conditions. Second, in a pictures/generate-label condition, labeling was encouraged; subjects were told to think of the label of each picture in preparation for a picture and word recognition test. Third, in a picture + word/read condition, subjects saw slides displaying the item's label beneath each drawing and were instructed to read each label to themselves in preparation for a picture and word recognition test. Finally, a word/read condition was included to provide a baseline and to permit comparison with Experiment 1. Subjects in each condition then received either a word fragment completion or a free recall test. 
Assuming that covert labeling produces priming, the picture/study-details condition should produce little or no priming because labeling is discouraged. The picture/ generate-label condition should produce an intermediate level of priming, and the picture + word/read and word/ read conditions should produce the most priming.

The free recall test was included (1) to demonstrate the picture superiority effect and replicate the dissociation obtained in Experiment 1, and (2) to provide evidence that subjects were following instructions. The free recall conditions allowed us to address a further question, which is orthogonal to our main inquiry but interesting in its own right. Specifically, the free recall conditions permitted us to ask whether the generation effect (Slamecka \& Graf, 1978) actually underlies the picture superiority effect. If subjects expect a recall test when they study pictures, they probably implicitly generate the names of the pictures, which are the actual stimuli to be recalled. Dual code theory postulates that pictures are recalled better than are words because both imaginal and verbal codes are accessed. However, it may be that it is the act of generation (rather than the automatic arousal of a verbal code) that causes the picture superiority effect. For example, Davies, Milne, and Glennie (1973) compared the effects of dual coding in four study conditions: words presented alone, words followed by their pictures, pictures presented alone, and pictures followed by their names. On a free recall test, words followed by their pictures were retained no better than were words presented alone, and both of these conditions produced poorer retention than the picture-alone and pictures-followed-by-names conditions. The authors suggested that picture superiority results from spontaneously generating picture names, not from activating dual codes. Our Experiment 2 tested this hypothesis more directly by requiring subjects to actively label pictures. If the generation effect underlies the picture superiority effect, then recall should be higher in the picture/ generate-label than the picture + word/read condition, because, although both conditions activate verbal codes, generation occurs only in the former.

\section{Method}

Subjects and Design. The participants were 228 Purdue University students who had not participated in Experiment 1 and who received credit toward a requirement in introductory psychology. All factors were manipulated between subjects. Twenty-one subjects in each of the four study conditions performed the word fragment completion test, and 36 in each condition performed the free recall test. (More subjects were tested in the free recall condition because of greater variability in the data.) All subjects were native English speakers and had normal or corrected-to-normal vision.

Materials. Sixty-nine items were divided into three sets equated for fragment completion rate, frequency (Kuðera \& Francis, 1967), and labeling consistency. Norms for labeling consistency were established by showing drawings of all items to a separate group of 50 subjects and asking them to write a one-word label for each item. Consistency ranged from $88 \%$ to $100 \%$, with an average of $97 \%$. A word fragment with a unique solution was created for each item. The fragment completion rate ranged from $19 \%$ to $49 \%$, with an average of $32 \%$. Word frequency ranged from 0 to 38 per million, with an average of 6.7 . Three different lists were created by designating two item sets as studied and one set as nonstudied items in each list, with sets counterbalanced across lists. Each list was studied by an equal number of subjects in all study conditions within each test condition.

Three different slides were made for each item. Picture slides were simple black-on-white line drawings. Forty were selected from the Snodgrass and Vanderwart (1980) set, and the remainder were drawn in a similar style. Word slides contained the item label typed in black lowercase letters. Picture + word slides contained the label typed in the same black lowercase font below the drawing of each item.

Three slides were also made for each of 10 buffer items ( 5 pictures, 5 words) selected from the Snodgrass and Vanderwart (1980) set. The same 5 items were presented in the same order at the beginning and end of each list. Study items for each list were randomly ordered, but the same order was maintained for each list in all four study conditions.

The word fragment completion test contained the 69 fragments typed in random order in the same lowercase font that appeared on the picture + word and word-only slides. The three test pages were collated in all six possible orders; each order was used an approximately equal number of times in all conditions. Subjects who received the free recall test were given a blank sheet of paper.

Randomly selected subsets of items were used to make simple versions of the anticipated recognition tests for all study conditions. The sham tests were given after the recall or fragment completion tests in order to fulfill the subjects' expectations, but these data were not scored because item selection was unsystematic and performance was contaminated by the previous target tests.

Procedure. One to 6 subjects were tested at a time. They were seated in a darkened room 5-10 ft from the slide screen. The first buffer item, an accordion, was displayed in the appropriate format on the screen as the experimenter read the instructions. Subjects in the picture/study-details condition were told that they were going to see a series of drawings and then receive a picture discrimination test. They were instructed to study pictorial details, such as shading, orientation, amount of detail, and black and white areas. To illustrate the strategy, the experimenter described some details of the displayed accordion that would be important to notice in order to perform the test. Subjects were then shown an example of the expected test and told that some of the discriminations would be quite difficult. Thus, they were told to focus their attention only on the details of the drawings.

The picture/generate-label subjects were told that they would see a series of drawings and that they were to say the name of each silently to themselves as they viewed the slides because they would later receive a picture recognition test for some of the items and a word recognition test for other items. They were shown samples of each type of test and were advised that labeling each item would maximize their performance. The instructions for the picture+ word/read condition were essentially the same, except that subjects were told that they would see drawings with the item's label typed below each. They were instructed to look at each picture and read each label silently in order to maximize their performance on the picture and word recognition tests.

Finally, subjects in the word/read group were told that they would see a series of word slides and that they were to read each word to themselves. They were told that they would receive a word recognition test and were shown a sample of the test sheet.

Slides were presented with a Kodak carousel projector at the rate of $4.25 \mathrm{sec}$ per item, with a 0.75 -sec interstimulus interval. Subjects then received instructions for the unexpected fragment completion or free recall test. The fragment completion test was administered as in Experiment 1, except that subjects were allowed $15 \mathrm{sec}$ per item instead of $20 \mathrm{sec}$. Subjects taking the free recall 
test were allowed $7 \mathrm{~min}$; every minute they were told to draw a line beneath the last item recalled, and after $5 \mathrm{~min}$ they were encouraged to try to remember additional items. After completing the free recall or word fragment completion test, subjects took the expected recognition tests. After running several experimental sessions, a questionnaire about subjects' impressions of the fragment completion test was developed and administered to the remaining subjects.

The experiment was conducted by one male and two female experimenters. A Latin square was used to assign experimenters to study conditions, lists, and test types.

\section{Results and Discussion}

Results of Experiment 2 are presented in Table 2, which displays the free recall data and word fragment completion raw score and priming data for all four study conditions. Results are reported at $p<.01$ unless otherwise noted.

Word fragment completion. As in Experiment 1, the ANOVA on the fragment completion data was performed on priming levels (studied - nonstudied performance) for each subject, due to variability between groups in the baseline nonstudied completion rates. A one-way betweensubjects ANOVA revealed that the effect of study condition was significant $[F(3,80)=7.81, M S e=0.02]$. Planned comparisons revealed no significant difference between the picture/study-details and picture/generatelabel conditions, which was the critical test of the effect of covert labeling in this experiment. Furthermore, significantly less priming occurred in the picture/generatelabel than in the picture + word $/ \mathrm{read}$ condition $[t(40)=$ 3.45 , one-tailed], which did not differ from the word/read condition. Thus, manipulation of covert labeling of pictures did not affect the amount of priming. Large priming effects were obtained only when the subjects actually read the words. When subjects saw drawings, priming was the same whether they studied pictorial details in preparation for a picture discrimination test or silently generated the name of each picture to themselves.

The word fragment completion data replicated three important results in Experiment 1. First, the picture superiority effect was reversed in that studying words facilitated performance more than did studying pictures on the word fragment completion task. Second, the priming effects obtained for pictures in this experiment were virtually identical to those obtained in Experiment 1 when fragment completion was the first test (about 0.06), even though many of the items were different. Finally, even though picture priming was small, it was significantly greater than zero in both the picture/study-details and picture/generate-label conditions $[t(20)=1.98$, and $t(20)=2.12$, respectively, $p \mathrm{~s}<.05$, one-tailed]

Of course, the most obvious question regarding the instructional manipulation is whether it actually produced differences in covert labeling. Instructions to study pictorial details do not guarantee suppression of labeling. However, two pieces of evidence suggest that the instructions did affect labeling. First, free recall (discussed in detail below) was significantly higher for the subjects given the labeling instructions than for those told to study pictorial details. Thus, free recall showed the effects that were expected if subjects were following these instructions. Second, questionnaire data also suggest that subjects in the picture/generate-label condition were labeling items more than those in the picture/study-details condition. For example, subjects were asked to describe what they did or said to themselves as they studied each slide. In the picture/study-details group, only $17 \%$ (of 26 surveyed) explicitly reported saying the names of the pictures to themselves, whereas $84 \%$ (of 38 surveyed) in the picture/generate-label group explicitly reported doing so.

Surprisingly, covert labeling does not appear to be the mechanism through which pictures prime word fragments. This conclusion was examined further in Experiment 3.

Free recall. A one-way between-subjects ANOVA on the free recall data indicated that the effect of study condition was significant $[F(3,140)=8.99, M S \mathrm{e}=0.01]$. A Newman-Keuls test revealed that the picture/generatelabel condition produced performance significantly better than did all other conditions. (Newman-Keuls post hoc comparisons were used because specific predictions comparing all groups were not formulated.) Performance of the picture + word/read group was not statistically different from that of the picture/study-details group, but it was significantly better than that of the word/read group at the $p<.05$ level of significance. Thus, the picture superiority effect was obtained when pictures were either labeled or presented with their labels. Performance by subjects in the picture/study-details and word/read conditions was not significantly different.

Several aspects of the free recall data are worth noting. First, as mentioned above, the free recall data provide evidence that the study instructions affected label-

Table 2

Mean Word Fragment Completion and Free Recall Rates in Experiment 2

\begin{tabular}{lcccc}
\hline & \multicolumn{4}{c}{ Study Format/Instructions } \\
\cline { 2 - 4 } Test & $\begin{array}{c}\text { Picture/ } \\
\text { Study-Details }\end{array}$ & $\begin{array}{c}\text { Picture/ } \\
\text { Generate-Label }\end{array}$ & $\begin{array}{c}\text { Picture+ } \\
\text { Word/Read }\end{array}$ & Word/Read \\
\hline Word Fragment Completion & & & \\
Raw Scores & .34 & .38 & .47 & .56 \\
$\quad$ Studied & .28 & .33 & .29 & .36 \\
$\quad$ Nonstudied & .06 & .05 & .18 & .20 \\
Priming & .29 & .39 & .32 & .27 \\
Free Recall & & &
\end{tabular}


ing. Subjects who generated labels for pictures recalled significantly more items than did those who simply studied pictorial details. Thus, the free recall data permit the inference that some process, presumably covert labeling, was greater in the picture/generate-label than in the picture/study-details condition, as planned. Second, generating a picture's label produced a substantially larger picture superiority effect than did reading the label beneath the picture, which produced no better memory than did studying pictorial details. These results suggest that superior memory for pictures may partly be due to a generation effect. That is, whereas picture superiority was obtained when both verbal and imaginal codes were passively activated (picture + word/read), supporting Paivio's dual code hypothesis, a significantly greater mnemonic benefit was obtained when the verbal code was actively produced. The finding that label generation improved picture memory is consistent with other findings in the literature (Durso \& Johnson, 1980; Smith \& Magee, 1980).

\section{EXPERIMENT 3}

The failure of covert labeling to enhance priming in Experiment 2 was surprising because the finding seems incongruent with the fact that auditorily presented words produce significant priming. Roediger and Blaxton (in press) obtained a $16 \%$ priming effect from auditorily presented words, which was almost half the priming level obtained from visually presented words (28\%). In Experiment 2, covert labeling of pictures produced about the same level of priming as did simply viewing pictures $(5 \%$ vs. $6 \%$ ), which was only about one fourth the level obtained from visual presentations of the words (20\% priming). There is no obvious reason why auditory presentation should produce substantial priming in completing word fragments, whereas generating the word internally (covert labeling) should not. Experiment 3 was designed to provide a direct comparison of the effects of covert labeling with auditory input on word fragment completion priming. Subjects labeled pictures in four different ways: covert naming, silent mouthing, naming aloud, or printing. The silent mouthing condition was included to test for the effects of articulation without auditory input, and the printing condition to provide a comparison for the effects of visual input.

\section{Method}

Subjects and Design. Participants were 40 Purdue University students who received credit toward a requirement in introductory psychology. All subjects were native English speakers who had normal or corrected-to-normal vision and had not participated in either of the previous two experiments.

A one-way within-subjects design was employed with four labeling conditions: covert labeling, silent mouthing, naming aloud, and printing; the nonstudied baseline was included in the statistical analysis as the fifth level of this factor. All subjects received the word fragment completion test and then a free recall test.

Materials. Sixty-five pictures selected from those used in Experiment 2 were divided into five sets of 13 , approximately equated for word frequency ( 7 per million, Kučera \& Francis, 1967), label agreement $(97 \%)$, and nonstudied word fragment completion rate $(32 \%)$. The five sets of pictures were rotated through the nonstudied and four labeling conditions, creating five lists. Within each list, the order in which subjects performed the four labeling tasks was partially counterbalanced across four study blocks so that across subjects every task occurred in every block an equal number of times and every task appeared before and after every other task an equal number of times, creating four study orders for each list. Two subjects studied each of the 20 combinations of assignment of items to labeling conditions and order of labeling conditions.

The slides were arranged in four blocks in the slide tray, and each set of 13 slides was preceded and followed by two buffer pictures, so that a total of 17 items was studied within each labeling condition. Before each set of pictures, an instruction slide appeared to remind the subject of the labeling instructions for that block (i.e., "Think of name silently," "Move lips, no sound," "Name out loud," or "Print each name").

The 65 word fragments on the completion test were the same frames as those used in Experiment 2 and were arranged in random order on the test pages. The pages were collated in all possible orders and randomly distributed.

Procedure. Subjects were tested individually and were seated $5 \mathrm{ft}$ from the slide screen in a normally illuminated room. Slides were presented from a Kodak carousel projector for $6.25 \mathrm{sec}$ each, with a 0.75 -sec change time. Before each labeling condition, the experimenter read brief instructions explaining how to study the 17 pictures in the upcoming block. Before the covert labeling condition, subjects were instructed to "say the name of each drawing silently" to themselves. Before the mouthing condition, they were told to "move your lips as if you are saying the name, but do not make any sound." The experimenter demonstrated and the subject practiced this technique with the word accordion. Before the naming aloud condition, subjects were instructed to "say the name of each drawing out loud." Finally, before the printing condition, subjects were told to print the name of each item on a piece of lined paper supplied to them. The example accordion was printed at the top. In all conditions except covert labeling, the experimenter noted any discrepancies between the subjects' productions and the designated labels.

After viewing all the slides, subjects took the word fragment completion task in the same manner described for Experiment 2. They were not informed that the fragments were made from the labels of the drawings they had studied. After completing the fragment completion tests, subjects took a 10 -min free recall test during which they wrote the names of as many drawings as they could remember.

\section{Results and Discussion}

The word fragment completion and free recall rates are presented in Table 3. Results are reported at the $p<.01$ level of significance unless otherwise noted.

Experimenters' recordings of subject-generated labels during the mouthing, naming aloud, and printing condi-

Table 3

Mean Word Fragment Completion and Free Recall Rates in Experiment 3

\begin{tabular}{llllll}
\hline & \multicolumn{5}{c}{ Study Instructions } \\
\cline { 2 - 6 } \multicolumn{1}{c}{$\begin{array}{c}\text { Covert } \\
\text { Test }\end{array}$} & Labeling & Mouthing & $\begin{array}{c}\text { Naming } \\
\text { Aloud }\end{array}$ & Printing & Nonstudied \\
\hline Word Fragment & & & & & \\
Completion & & .46 & .44 & .54 & .38 \\
Raw scores & .43 & .46 & .06 & .16 & \\
Priming & .05 & .08 & .45 & .40 & \\
Free Recall & .46 & .39 & .45 &
\end{tabular}


tions indicated that subjects generated incorrect labels for $3 \%$ of the drawings. Scores on the word fragments for mislabeled pictures were not eliminated from the analyses because such errors could not be determined for covertly labeled items.

Word fragment completion. A one-way ANOVA on the fragment completion scores revealed a significant main effect $[F(4,156)=7.60, M S e=0.018]$. Planned comparisons revealed that the printing condition produced significantly more priming than did the covert labeling, mouthing, and naming aloud conditions $[t(39)=3.67$, $2.67,3.33$, respectively, one-tailed]. The latter three conditions were not significantly different from one another. One-tailed $t$ tests revealed significant priming in all four study conditions as compared with the nonstudied baseline: for covert labeling, $t(39)=1.98, p<.05$; mouthing, $t(39)=2.57$; naming aloud, $t(39)=2.23, p<.05$; printing, $t(39)=4.98$. Thus, labeling significantly enhanced priming above the level normally obtained for pictures (about 6\%) only when subjects actually saw the items' labels, that is, in the printing condition. Priming from auditory presentations may have been less in this experiment than in Roediger and Blaxton's (in press) experiment, either because of differences in auditory presentation (production in our experiment vs. listening in Roediger and Blaxton's) or because of differences in the difficulty of the word fragments (ours were more concrete and had higher baseline completion rates).

Free recall. A one-way ANOVA on the free recall data revealed a reliable difference among study conditions $[F(3,117)=2.68, M S e=0.018, p<.05]$. However, no between-group differences reached significance on a Newman-Keuls test ( $p>.05$ for all comparisons), suggesting that the differences were slight. (A Newman-Keuls test was performed because no specific pattern of differences was predicted for these conditions.) These data will not be discussed further because they are not of primary interest. Furthermore, they are contaminated by test order; that is, it is difficult to assess the effects of the prior word fragment completion test on free recall.

\section{EXPERIMENT 4}

In Experiment 1 picture superiority was obtained on the explicit free recall test, but was reversed on the implicit word fragment completion task. One possible explanation is that the factor controlling these effects is the explicit versus implicit nature of the tests; that is, perhaps pictures are more accessible than words via explicit tests, whereas words produce more priming on implicit tests. Alternatively, the important factor in obtaining the reversal may have been the type of processing tapped by the retrieval task; specifically, the word fragment test may be more sensitive to data-driven components of the study episode, whereas the free recall test is conceptually driven. In order to test between these alternatives, all subjects in Experiment 4 studied pictures and words and then received either a word fragment completion or a picture fragment identification test. Thus, all subjects received implicit tests, but the tests differed in the nature of the surface information presented.

\section{Method}

Subjects and Design. Subjects were 90 Purdue undergraduates participating for credit in introductory psychology. All were native English speakers with normal or corrected-to-normal vision who had not participated in any of the preceding experiments.

All subjects studied mixed lists of pictures and words. Then half the subjects received the word fragment completion test and half received the picture fragment identification test. Study format (pictures vs. words vs. nonstudied) was a within-subjects factor. The two retrieval tests were analyzed with separate ANOVAs.

Materials. Fifty-four critical items were selected from the Snodgrass and Vanderwart (1980) norms and our own pool of items. Most were the same as those used in the previous experiments. Picture fragments were created from the original drawing of each item by unsystematically eliminating parts of the picture and then testing identifiability with small groups of subjects who were instructed to provide a label for every picture. The picture fragments were altered and tested until approximately $25 \%$ could be identified without previous exposure, with individual items ranging from $4 \%$ to $43 \%$. Examples of the picture fragments are presented in Figure 1. Word fragments had an average baseline completion rate of $31 \%$, with individual items ranging from $17 \%$ to $48 \%$.

Items were divided into three sets approximately equated for word fragment and picture fragment identification baselines, labeling agreement (96\%), and word frequency ( 7 per million, Kucera \& Francis, 1967). Items were rotated through the picture, word, and nonstudied conditions creating three different lists. Items were randomly ordered with the restriction that no more than three pictures or words appear sequentially. Two words and two pictures were placed at the beginning and end of each list, and these eight buffer items remained in the same order for each list. Fifteen subjects in
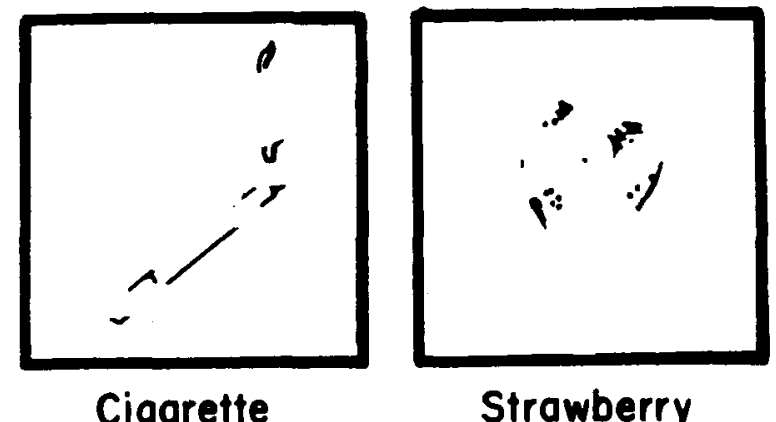

Cigarette

Strawberry
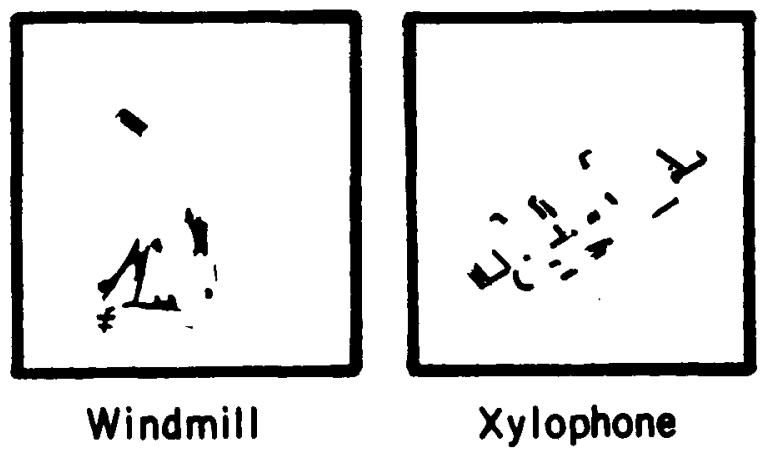

Figure 1. Examples of picture fragments used in Experiment 4. Actual size was $1 \frac{1 / 2}{11 / 2}$ in. 
each test condition (picture or word fragment) studied each of the three lists.

The picture fragment identification test comprised 11 pages with five picture fragments on each page; one filler fragment was included to create an equal number of items on each page. The word fragment completion test contained 27 fragments on each page. For both tests, all items were randomly ordered, the pages were collated in all possible orders, and the test booklets were randomly distributed.

Procedure. Subjects were tested in groups of 5-15, seated 5$15 \mathrm{ft}$. from the slide screen. Slides were presented in a darkened room from a Kodak carousel projector at the rate of $4.25 \mathrm{sec}$, with a 0.75 -sec change time. Subjects were told that they were going to be performing some tasks that would help us prepare materials for future research projects, and that they should pay close attention to each slide; they were not informed that they would receive a test. After viewing the slides, subjects were given a 100 -item word fragment completion test as a filler task; none of the fragments were from the slides. The purpose of this task was to better disguise the fact that the second fragment test was related to the studied items, a technique employed by other researchers investigating implicit memory (e.g., Graf \& Schacter, 1985). Next, subjects received either the word fragment completion or picture fragment identification test for the critical items. They were not told that some of the items were from the slides. In both groups, subjects were allowed $20 \mathrm{sec}$ to complete or identify each item. They used a cover sheet to hide the upcoming items and were instructed not to work ahead or return to any items.

\section{Results and Discussion}

The completion and identification rates and priming rates for each study condition are presented in Table 4 . Statistics are reported at the $p<.01$ level of significance unless otherwise indicated.

The word fragment completion data replicated the reversal of the picture superiority effect obtained in Experiments 1 and 2 . The effect of study format was significant $[F(2,44)=26.65, M S e=0.01]$. Planned comparisons revealed that words produced significantly more priming than did pictures $[t(44)=4.17$, one-tailed $]$ and that pictures produced significant priming compared with the nonstudied items $[t(44)=2.92$, one-tailed].

The picture fragment test was scored for the number of items correctly identified. Subjects rarely identified a picture fragment as an item from the study list different from the correct item (e.g., after studying both elephant and penguin, identifying the elephant fragment as a penguin). Such confusions constituted only $1 \%$ of the total

Table 4

Picture Fragment Identification and Word Fragment Completion Rates from Experiment 4

\begin{tabular}{lrcc}
\hline & \multicolumn{3}{c}{ Study Format } \\
\cline { 2 - 3 } Test & Picture & Word & Nonstudied \\
\hline Word Fragment Completion & & \\
$\quad$ Raw scores & .54 & .64 & .47 \\
Priming & .07 & .17 & \\
Picture Fragment Identification & & \\
$\quad$ Raw scores & .39 & .25 & .22 \\
Priming & .17 & .03 & \\
\hline
\end{tabular}

responses, and the rate was the same for pictures and words.

On the picture fragment identification test, the effect of study format was significant $[F(2,44)=26.10, M S e=$ $0.01]$. Planned comparisons revealed that pictures produced significantly more priming than did words $[t(44)=5.38$, one-tailed], but words were not different from nonstudied items. Thus, the picture superiority effect was reinstated on an implicit memory test.

These results suggest that the factor controlling the dissociation between the effects of pictures and words on the retrieval tests employed here is not whether the tests were explicit or implicit, but the type of stimulus processing to which the tests are sensitive. Specifically, the fragment tests employed here are primarily data-driven in that they reflect retention for the processing of surface features of the pictures and words. Thus, pictures and words produced the most priming on the tests that better matched their surface features.

\section{GENERAL DISCUSSION}

The results of these experiments revealed that (1) the picture superiority effect can be reversed by changing only the retrieval task; (2) the important factor determining whether pictures or words produce better retrieval on the tasks employed here is not whether tasks are implicit or explicit, but rather whether the retrieval tests tap memory for the processing of physical or conceptual attributes of the encoding episode; (3) a reliable, although small, priming effect from pictures occurs in the word fragment completion task, and (4) covert labeling is not the mechanism by which pictures prime word fragments. The significance of these results will be discussed in turn below.

Experiments 1 and 2 demonstrated that the picture superiority effect can be reversed by changing the retrieval task. Picture superiority is usually attributed to encoding differences, but the obtained reversal shows that retrieval factors are also important. In the two experiments reported here, this fact was demonstrated by testing memory with an implicit, data-driven task (i.e., the word fragment completion task).

Why should a word fragment completion test favor the retrieval of words over pictures, whereas a free recall test produces the reverse effect? These results can be interpreted on the assumption that a free recall test is more conceptually driven (more sensitive to conceptual components of the memory trace), whereas the word fragment completion test is more data-driven (relies more heavily on the match of surface features between study and test stimuli). Thus, the word fragment completion test favors word over picture study because, when words are read, there is greater overlap between the surface features of the study event and the word fragment.

One might argue that the manipulation was contrived, because the fragment completion test simply compared memory for stimuli that had been seen (words) to memory 
for stimuli that had not been seen (names of pictures). However, recall Madigan's (1983) finding that when retention was tested with a word recognition test, items that had been studied as pictures were recognized significantly more accurately than those studied as words. On the word recognition test, the physical match between the studied words and the test stimuli is even greater than on the fragment completion task (e.g., pyramid vs. -yr_mi , $_{\text {, yet }}$ words produced poorer performance than did pictures on the word recognition test. If the difference in the physical match between study and test stimuli accounted for our results, then words should also be remembered better than should pictures on the word recognition test. Clearly, word fragment completion must involve a different retrieval process or tap a different component of the memory trace than do free recall and recognition.

If picture-word differences on the word fragment completion task can be explained by suggesting that the test is data-driven, then how can picture superiority on the free recall test be explained within the same theoretical framework? That is, if free recall is tapping memory for conceptual components of stimulus processing, why should pictures be recalled better than words?

Several researchers (Intraub \& Nicklos, 1985; Nelson, 1979; Smith \& Magee, 1980) have suggested that pictures contact semantic (meaning) codes in memory more directly than do words, but do not necessarily contact label codes. Conversely, words contact label codes directly, but do not necessarily activate semantic codes to the same extent as do pictures. This suggestion is supported by the finding that superordinate categories are identified faster for pictures than for words (Pellegrino, Rosinski, Chiesi, \& Siegel, 1977; Smith \& Magee, 1980), but words are named faster than are pictures (Smith \& Magee, 1980). Additionally, as mentioned previously, picture retention may benefit from the generation of picture names. Thus, viewing pictures can be considered a more conceptual task than reading words. The fact that words are remembered as well as pictures when semantic encoding is forced by an orienting task (Durso \& Johnson, 1980; Smith \& Magee, 1980) also lends support to this notion. Thus, the mnemonic benefit of pictures on tests that tap conceptual or semantic components of the memory trace may be attributed to the more elaborative nature of picture processing.

All other things being equal, standard methods of testing picture and word memory, such as free recall and recognition, may favor retrieval of information encoded in pictorial formats because performance on such tasks benefits from conceptually driven processing. Thus, picture superiority may be a special case of the general finding that stimuli that are encoded more elaborately or more "deeply" are remembered better on tests such as free recall and recognition. But if a retrieval test taps memory for a nonsemantic component of the memory trace, such as its graphemic features, then semantic elaboration or deep processing is less beneficial to performance.
Morris, Bransford, and Franks (1977) coined the term "transfer appropriate processing" to describe the fact that what constitutes mnemonically effective stimulus processing depends upon the goals of the learning episode, as determined by the retrieval task. Kolers and Roediger (1984) expressed a similar idea in their suggestion that memory will be "good" to the extent that the procedures engaged at encoding and retrieval are similar. These ideas underlie our suggestion that if pictures do contact semantic memory more directly and produce semantically richer episodic traces than do words, then tests favoring retrieval of conceptual or semantic information, such as free recall or recognition, should contribute to picture superiority effects. Conversely, when memory is measured with a data-driven test that favors retrieval of graphemic features of verbal stimuli, such as word fragment completion, the overlap between encoding processes and retrieval demands is relatively smaller for pictures than for words, so words are retained better than are pictures. Other findings congruent with this interpretation are the attenuation of repetition priming from pictures in the lexical decision task (Kroll \& Potter, 1984; Scarborough et al., 1979) and the fact that pictures are less effective than are words in lowering perceptual identification thresholds for words (Morton, 1979; Winnick \& Daniel, 1970) or in increasing perceptual identification accuracy (Durso \& Johnson, 1979; Kirsner et al., 1986).

The second major outcome of these experiments was that pictures produced small but reliable priming effects on the word fragment completion test. If the test was completely data-driven, pictures should have produced no priming because there is no overlap between the physical features of pictures and word fragments. Results of Experiments 2 and 3 led us to conclude that covert labeling did not produce this priming because several forms of labeling did not affect priming levels. That is, picture priming was not enhanced by either covertly labeling, mouthing, or saying aloud the pictures' names. Only when the printed form of the label was seen was picture priming significantly increased (i.e., when the label was read with the picture or was printed by the subject). Although these results do not clarify the reason that pictures prime word fragments, they nicely illustrate the data-driven component in fragment completion. That is, fragment completion improved significantly only when subjects processed the visual physical features of the words themselves.

If labeling per se does not produce picture priming, then what is the source of the effect? It is possible that the word fragment completion task does have a conceptual component. As mentioned before, we are suggesting that retrieval tasks may be classifiable along a continuum representing the relative amounts of data-driven and conceptually driven processing. Some of the experimental results discussed previously can be explained by suggesting that word fragment completion taps, to a small degree, a conceptual component of the memory trace. For example, a plausible explanation of the cross modality prim- 
ing effect obtained by Roediger and Blaxton (in press) is that it reflects sensitivity to conceptual components, whereas the additional priming obtained from visual presentations reflects sensitivity to physical components of episodic traces. This account rests on the assumption that auditory and visual presentations do not differentially affect the nature of the conceptual information recorded in an episodic trace, but do affect the record of the physical medium transmitting that information.

The third contribution of these experiments is their implications for understanding dissociations between explicit and implicit memory measures. In Experiment 4, a dissociation between two implicit measures was obtained. Pictures produced more priming than did words on the picture fragment identification test, whereas the reverse was true on the word fragment completion test. Thus, the differential effects of pictures and words on retrieval obtained in Experiment 1 cannot be attributed to the implicit versus explicit nature of the retrieval tasks per se. Rather, the important factor that determines whether pictures or words are retained better is the memory attributes tapped by the retrieval test. Pictures are remembered better than are words on explicit free recall because free recall is more sensitive to conceptually driven processing. As discussed above, pictures produce richer encodings than do words on this dimension. However, because implicit fragment completion tests are primarily data-driven, performance is determined by the degree to which the data presented at test match those presented at study. Thus the differential effects of picture and word study depend on the physical features of the test fragments. These results lead us to suggest that an important distinction underlying the dissociations obtained between implicit and explicit memory tests is that implicit tests tend to be data-driven, whereas explicit tests tend to be conceptually driven. However, one can construct data-driven explicit tests and conceptually driven implicit tests, as did Blaxton (1985).

Finally, the experiments reported here have broader implications for theories of memory. The reversal of the picture superiority effect on the word fragment completion test is one example of the large interactions that exist between encoding manipulations and test types. In Experiments 1,2 , and 3 , there was a negative correlation between free recall and priming in word fragment completion as a function of encoding conditions. That is, encoding conditions that produced more priming simultaneously produced worse free recall. These experiments, and many other studies cited in this paper, demonstrate that memory appears to have very different properties, depending on how it is measured. In our opinion, explaining such dissociations is a critical problem for theory. The procedural framework emphasizing transfer appropriate processing (briefly stated above and elaborated elsewhere, e.g., Kolers \& Roediger, 1984; Morris et al., 1977; Roediger \& Blaxton, 1987) provides a broad interpretation of these phenomena. We anticipate more precise theories specifying processes underlying different tasks.

\section{REFERENCES}

BaBbitt, B. C. (1982). Effect of task demands on dual coding of pictorial stimuli. Joumal of Experimental Psychology: Leaming, Memory, \& Cognition, 8, 73-80.

BLAXTON, T. A. (1985). Investigating dissociations among memory measures: Support for a transfer appropriate processing framework. Unpublished doctoral dissertation, Purdue University, Lafayette, IN.

Borges, M. A., Stepnowsky, M. A., \& Holt, L. H. (1977). Recall and recognition of words and pictures by adults and children. Bulletin of the Psychonomic Society, 9, 113-114.

Craik, F. I. M., \& Tulving, E. (1975). Depth of processing and the retention of words in episodic memory. Joumal of Experimental Psychology: General, 104, 268-294.

Davies, G. M., Milne, J. E., \& Glennie, B. J. (1973). On the significance of "double encoding" for the superior recall of pictures to names. Quarterly Journal of Experimental Psychology, 25, 413-423.

Durso, F. T., \& Johnson, M. K. (1979). Facilitation in naming and categorizing repeated pictures and words. Journal of Experimental Psychology: Human Learning \& Memory, 5, 449-459.

Durso, F. T., \& Johnson, M. K. (1980). The effects of orienting tasks on recognition, recall, and modality confusion of pictures and words. Joumal of Verbal Learning \& Verbal Behavior, 19, 416-429.

GraF, P., \& MANDler, G. (1984). Activation makes words more accessible, but not necessarily more retrievable. Journal of Verbal Learning \& Verbal Behavior, 23, 553-568.

Graf, P., \& Schacter, D. L. (1985). Implicit and explicit memory for new associations in normal and amnesic subjects. Journal of Experimental Psychology: Learning, Memory, \& Cognition, 11, 501-518.

Graf, P., Shimamura, A. P., \& SQuire, L. R. (1985). Priming across modalities and priming across category levels: Extending the domain of preserved function in amnesia. Journal of Experimental Psychology, 11, 386-396.

Graf, P., Squire, L. R., \& Mandler, G. (1984). The information that amnesic patients do not forget. Journal of Experimental Psychology: Learning, Memory, \& Cognition, 10, 164-178.

INTRAUB, H., \& NiCKLOS, S. (1985). Levels of processing and picture memory: The physical superiority effect. Journal of Experimental Psychology: Learning, Memory, \& Cognition, 11, 284-298.

$J_{A C O B Y}$ L. L. (1983). Remembering the data: Analyzing interactive processes in reading. Journal of Verbal Learning \& Verbal Behavior, 22, 485-508.

JACOBY, L. L., \& DALLAS, M. (1981). On the relationship between autobiographical memory and perceptual learning. Joumal of Experimental Psychology: General, 111, 306-340.

Kirsner, K., Milech, D., \& Standen, P. (1983). Common and modality-specific processes in the mental lexicon. Memory \& Cognition, 11, 621-630.

Kirsner, K., Milech, D., \& Stumpfel, V. (1986). Word and picture identification: Is representational parsimony possible? Memory \& Cognition, 14, 398-408.

Kolers, P. A., \& Roediger, H. L. (1984). Procedures of mind. Journal of Verbal Learning \& Verbal Behavior, 23, 425-449.

Kroll, J. F., \& PotTer, M. C. (1984). Recognizing words, pictures and concepts: A comparison of lexical, object and reality decisions. Journal of Verbal Leaming \& Verbal Behavior, 23, 39-66.

Kučera, H., \& Francis, W. N. (1967). Computational analysis of present-day American English. Providence, RI: Brown University Press.

Madigan, S. (1983). Picture memory. In J. C. Yuille (Ed.), Imagery, memory and cognition: Essays in honor of Allan Paivio (pp. 65-89). Hillsdale, NJ: Erlbaum.

MCGEоCH, J. A. (1942). The psychology of human learning. New York: Longmans, Green.

Morris, C. D., Bransford, J. D., \& Franks, J. J. (1977). Levels of processing versus transfer appropriate processing. Journal of Verbal Learning \& Verbal Behavior, 16, 519-533.

MORTON, J. (1979). Facilitation in word recognition: Experiments causing change in the logogen model. In P. A. Kolers, M. E. Wrolstead, 
\& H. Bouma (Eds.), Processing of visible language (Vol. 1, pp. 259268). New York: Plenum Press.

NELSON, D. L. (1979). Remembering pictures and words: Appearance, significance, and name. In L. S. Cermak \& F. I. M. Craik (Eds.), Levels of processing in human memory (pp. 45-76). Hillsdale, NJ: Erlbaum.

Nelson, D. L., ReEd, U. S., \& McEvoy, C. L. (1977). Learning to order pictures and words: A model of sensory and semantic encoding. Journal of Experimental Psychology: Human Leaming \& Memory, 3, 485-497.

Nelson, D. L., Reed, U. S., \& Waluing, J. R. (1976). Picture superiority effect. Joumal of Experimental Psychology: Human Learning \& Memory, 2, 523-528.

Parvio, A. (1969). Mental imagery in associative learning and memory. Psychological Review, 76, 241-263.

PAIvio, A. (1971). Imagery and verbal processes. New York: Holt, Rinehart \& Winston.

PAIVIo, A. (1973). Imagery in recall and recognition. In J. Brown (Ed.), Recall and recognition (pp. 103-129). New York: Wiley.

Paivio, A. (1983). The empirical case for dual coding. In J. C. Yuille (Ed.), Imagery, memory and cognition (pp. 307-332). Hillsdale, NJ: Erlbaum.

PaIvio, A. (1986). Mental representation: A dual coding approach. New York: Oxford.

Paivio, A., Csapo, K. (1971). Short-term sequential memory for words and pictures. Psychonomic Science, 24, 50-51.

PaIvio, A., \& CSAPO, K. (1973). Picture superiority in free recall: Imagery or dual coding? Cognitive Psychology, 5, 176-206.

Paivio, A., Rogers, T. B., \& Smythe, P. C. (1968). Why are pictures easier to recall than words? Psychonomic Science, 11, 137-138.

Pellegrino, J. W., Rosinski, R. R., Chiesi, H. L., \& Siegel, A. (1977). Picture-word differences in decision latency: An analysis of single and dual memory models. Memory \& Cognition, 5, 383-396.

RoEdiger, H. L., \& BLAXTon, T. A. (1987). Retrieval modes produce dissociations in memory for surface information. In D. S. Gorfein \& R. R. Hoffman (Eds.), The Ebbinghaus Centennial Conference (pp. 349-379). Hillsdale, NJ: Erlbaum.

RoEdiger, H. L., \& BLAXTON, T. A. (in press). Effects of altering sur- face features on priming in word fragment completion: Evidence for data-driven processing. Memory \& Cognition.

Scarborough, D. L., Cortese, C., \& Scarborough, H. S. (1977). Frequency and repetition effects in lexical memory. Journal of Experimental Psychology: Human Perception \& Performance, 3, 1-17.

Scarborough, D. L., Gerard, L., \& Cortese, C. (1979). Accessing lexical memory: The transfer of word repetition effects across task and modality. Memory \& Cognition, 7, 3-12.

Slamecka, N. J., \& Graf, P. (1978). The generation effect: Delineation of a phenomenon. Journal of Experimental Psychology: Human Learning \& Memory, 4, 592-604.

SMith, M. C., \& MAGEE, L. E. (1980). Tracing the time course of picture-word processing. Journal of Experimental Psychology: General, 109, 373-392.

SNODGRASS, J. G., MCCLURE, P. (1975). Storage and retrieval properties of dual codes for pictures and words in recognition memory. Journal of Experimental Psychology: Human Learning \& Memory, 1, 521-529.

SNODGRAss, J. G., \& VANDERWART, M. (1980). A standardized set of 260 pictures: Norms for name agreement, image agreement, familiarity, and visual complexity. Journal of Experimental Psychology: $\mathrm{Hu}$ man Learning \& Memory, 6, 174-215.

Tulving, E., Schacter, D. L., \& Stark, H. A. (1982). Priming effects in word-fragment completion are independent of recognition memory. Journal of Experimental Psychology: Learning, Memory, \& Cognition, 8, 336-342.

Tulving, E., Thomson, D. M. (1973). Encoding specificity and retrieval processes in episodic memory. Psychological Review, 80, 352-373.

Warrington, E. K., \& WeIsKrantz, L. (1970). Amnesic syndrome: Consolidation or retrieval? Nature, 228, 628-630.

Winnick, W. A., \& DANIEL, S. A. (1970). Two kinds of response priming in tachistoscopic recognition. Journal of Experimental Psychology, 84, 74-81.

(Manuscript received June 23, 1986; revision accepted for publication November 3, 1986.) 